
\title{
28 Research Suare \\ Eco-Friendly Chitosan@Silver/Plant Fiber Membranes for Masks with Thermal Comfortability and Self-Sterilization
}

\section{Qian Zou}

Sichuan University - Wangjiang Campus: Sichuan University

\section{Yinuo Gai}

Chengdu Yucai NO.7 School Xuedao Branch

\section{Xiaotang Gai}

Sichuan university

Siwei Xiong

Sichuan university

\section{Nanjun Wei}

Sichuan university

\section{Mengying Jiang}

Sichuan university

\section{Liye Chen}

Sichuan university

\section{Yang Liu}

Sichuan university

Jinggang Gai ( $\nabla$ gaijinggang201909@163.com )

Sichuan University - Wangjiang Campus: Sichuan University

\section{Research Article}

Keywords: chitosan@silver core-shell fibers, COVID-19, eco-friendly masks, thermal comfort, selfsterilization

Posted Date: November 29th, 2021

DOI: https://doi.org/10.21203/rs.3.rs-1043385/v1

License: (c) (i) This work is licensed under a Creative Commons Attribution 4.0 International License.

Read Full License 


\section{Abstract}

The surgical masks have been essential consumables for public in the COVID-19 pandemic. However, long-time wearing masks will make wearers feel uncomfortable and massive discarded nonbiodegradable masks lead to a heavy burden on our environment. In this paper, we adopt degradable chitosan@silver (CS@Ag) core-shell fibers and plant fibers to prepare an eco-friendly mask with excellent thermal comfort, self-sterilization, and antiviral effects. The thermal network of CS@Ag core-shell fibers highly improves the in-plane thermal conductivity of masks, which is 4.45 times higher than that of commercial masks. Because of the electrical conductivity of Ag, the fabricated mask can be electrically heated to warm the wearer in a cold environment and disinfect COVID-19 facilely at room temperature. Meanwhile, the in-situ reduced silver nanoparticles (AgNPs) endow the mask with superior antibacterial properties. Therefore, this mask shows a great potential to address the urgent need for a thermally comfortable, antibacterial, antiviral, and eco-friendly mask.

\section{Introduction}

At present, the world is amid a pandemic caused by a novel strain of 2019 coronavirus (COVID-19) (Kumar et al., 2021). Wearing surgical masks is an effective safeguard for our health in public (Liao et al., 2021a). According to the report (Prata et al., 2020), approximately 129 billion surgical masks are used every month worldwide. However, the filter layer of these surgical masks is generally polypropylene (PP) nonwovens, which takes over 10 years to degrade in landfills and brought much burden on the environment (Huang et al., 2020). Besides, PP nonwovens have poor thermal conductivity and lack antibacterial activity (Chen et al., 2016b). In hot environments, the hot and humid air cushion generated under the mask hinders normal breathing and cause much discomfort to the wearers (Liao et al., 2021b; Morabito et al., 2020; Yang et al., 2017a). Even worse, moist and warm masks provide a fertile environment for bacteria to multiply, posing an additional risk of infection to the wearer (Huang et al., 2020; Xiong et al., 2021). Therefore, developing a degradable face mask with thermal comfort and antibacterial activity is an urgent and significant challenging issue worldwide.

Biodegradable polymers have been developed purposely for filter layers of surgical masks, such as polylactic acid (Patil et al., 2021), poly(butylene succinate) (Choi et al., 2021), and polyvinyl alcohol (Li et al., 2021). However, pure polymer masks generally have poor thermal conductivity and antibacterial activity (Chen et al., 2016a; Guo et al., 2020). To fabricate thermal comfortable masks, Yang et al. (Yang et al., 2020) used electrospinning to prepare polyacrylonitrile/polyetherimide (PAN/PEI) nanofibrous membrane with ultralight mass and high porosity. The results of thermal infrared transmittance showed the PAN/PEI nanofibrous membrane possessed good radiative cooling property. Yang et al. (Yang et al., 2017b) transferred nylon-6 nanofibers to needle-punched nanofibers on nanoporous polyethylene (nanoPE) and manipulated the thermal properties by changing the thickness of the fiber. In terms of enhancing the antibacterial activity of masks, Huang et al. (Huang et al., 2020) used laser-induced graphene to improve the antibacterial rate of masks to $81 \%$. Combined with the photothermal effect, the antibacterial rate could attain 99.998\%. Kumar et al. (Kumar et al., 2020) deposited thin copper@ZIF-8 
core-shell nanowires (Cu@ZIF-8 NWs) on the filter media of masks. Cu@ZIF-8 NWs exhibited 86\% inhibition of Streptococcus mutans and $91 \%$ inhibition of Escherichia coli $(E$. coli) bacterial growth, and thus the number of bacterial colonies on the Cu@ZIF-8 NWs functionalized masks declined. In our previous group work (Xiong et al., 2021), we introduced quaternary ammonium salt/hexagonal boron nitride (QAC/h-BN), an antibacterial functionalized thermally conductive filler, into PP non-woven to obtain multifunctional masks with both outstanding thermal comfort and antibacterial activity. The thermal conductivity of the prepared QAC/h-BN/PP fibrous membrane is $706.5 \%$ higher than commercial PP non-woven fabric. Meanwhile, the antibacterial rates can reach $99.3 \%$ for $E$. coli ) and $96.1 \%$ for Staphylococcus aureus (S. aureus). Unfortunately, the raw materials of masks are non-degradable, and the antiviral effect of antibacterial agents on the COVID-19 is undefined.

To further satisfy the degradability, here, we adopted chitosan (CS) as the substrate to prepare a mask with both thermal comfort and antibacterial activity. Chitosan, a polysaccharide extracted from natural chitin, is a known biopolymer with antibacterial activity against Gram-negative bacteria and Grampositive bacteria (Zou et al., 2021). Due to the presence of active amino and hydroxyl groups, it presents unique polycation, chelating and film-forming properties (Abdelgawad et al., 2014). Therefore, it is an excellent replacement material for masks. Because of its good synergistic antibacterial effect with silver nanoparticles (AgNPs), CS-AgNPs nanocomposites have been reported to be used in wound dressing (Liu et al., 2020b), sustained-release drugs (Mohammed et al., 2017), water treatment (Mohammadzadeh Pakdel and Peighambardoust, 2018), etc. However, as far as we know, few studies have considered the use of CS-AgNPs nanocomposites as the raw materials for masks.

In this work, CS fibers were used as the carrier of in-situ reduced silver nanoparticles (AgNPs) to produce CS@Ag core-shell fibers. Then, CS@Ag core-shell fibers are connected by plant fibers to form a continuous network in the membranes. Because of skyscraping thermal conductivity, electrical conductivity, and antibacterial activity of silver (Ag) (Parida et al., 2020; Shen and Feng, 2018; Suh et al., 2019), CS@Ag core-shell fibers network imparts masks the same excellent performance. In a hot environment, CS@Ag/plant fiber membranes with excellent thermal conductivity can dissipate heat for the wearer. In a cold environment, CS@Ag/plant fiber membranes can generate electric heat after being energized, thereby warming the wearer. And it can be electrically heated to above $80^{\circ} \mathrm{C}$, making disinfection of COVID-19 facilely. The excellent antibacterial activity makes CS@Ag/plant fiber membrane achieve self-sterilization effect. Being multifunctional, CS@Ag/plant fiber membranes exhibit great potential to be applied to the filter layer of masks. Masks with this kind of filter layer will be more friendly to the environment, hence providing better sustainability.

\section{Materials And Methods}

2.1. Materials. Chitosan (CS) fibers with diameters of 10 20 $\mu \mathrm{m}$ and natural plant fibers with diameters of 5 20 $\mu \mathrm{m}$ were provided by Wuhan Textile University. Silver nitrate $\left(\mathrm{AgNO}_{3}\right)$, ammonia solution $\left(\mathrm{NH}_{4} \mathrm{OH}\right)$, and D-Glucose $\left(\mathrm{C}_{6} \mathrm{H}_{12} \mathrm{O}_{6} \cdot \mathrm{H}_{2} \mathrm{O}\right)$ were procured from Chengdu Kelon Chemicals Co., Ltd (Chengdu, 
China), and they were of analytical grade. $1 \mathrm{H}, 1 \mathrm{H}, 2 \mathrm{H}, 2 \mathrm{H}$-Perfluor odecyltr im ethoxysilane $\left(\mathrm{C}_{13} \mathrm{H}_{13} \mathrm{~F}_{17} \mathrm{O}_{3} \mathrm{Si}\right.$, PFDTMS) was purchased from Adamas-beta Reagents Co. Ltd.

2.2. Preparation of CS@Ag core-shell fibers. CS@Ag core-shell fibers were prepared as shown in Figure 1. First, a certain amount of $\mathrm{AgNO}_{3}$ was dissolved in $100 \mathrm{~mL} \mathrm{H} \mathrm{O}$, and enough ammonia solution was added dropwise until the precipitation disappeared to prepare a silver ammonia solution. Glucose whose mass is three times the mass of $\mathrm{AgNO}_{3}$ is dissolved in $20 \mathrm{~mL} \mathrm{H} \mathrm{H}_{2} \mathrm{O}$ to prepare a reducing agent solution. Secondly, $0.5 \mathrm{~g}$ of CS fiber was immersed in silver ammonia solution for $10 \mathrm{~min}$ to make the CS fiber chelated silver ions $\left(\mathrm{Ag}^{+}\right)$. Then the solution was stirred and heated at $50{ }^{\circ} \mathrm{C}$ for $30 \mathrm{~min}$. In this process, the CS fiber itself in-situ reduced a small amount of $\mathrm{Ag}^{+}$into silver nanoparticles (AgNPs) to provide crystal nucleation sites for subsequent reactions. At this time, the color of fibers turned from white to light yellow. Finally, the glucose solution was added dropwise under continuous stirring and heating for $4 \mathrm{~h}$. The AgNPs rapidly grew on the crystal nucleation sites and evenly adhered to the surface of CS fibers. The color of CS fibers changed from light yellow to yellowish-brown and then to black. The treated CS fibers were filtered, washed with distilled water, and dried at $60^{\circ} \mathrm{C}$ for $2 \mathrm{~h}$ to obtain CS@Ag core-shell fibers. By controlling the addition of $\mathrm{AgNO}_{3}$, a series of CS@Ag core-shell fibers with different AgNPs loadings were prepared, denoted as CS@Ag-x, where $x$ was the volume fraction of AgNPs. By weighing the mass of CS fibers before and after the reaction, we calculated the $x$ values, which were $12,21,29$, and 36\%, corresponding to samples CS@Ag-12,CS@Ag-21, CS@Ag-29, and CS@Ag-36, respectively.

2.3. Preparation of CS@Ag/plant fiber membranes. $0.2 \mathrm{~g}$ of plant fibers and $1.4 \mathrm{~g}$ of CS@Ag core-shell fibers were placed in $100 \mathrm{ml}$ water, stirred evenly, and filtered with suction, as shown in Figure 1. After drying, the CS@Ag/plant fiber membranes are obtained. After that $0.5 \mathrm{~g}$ PFDTS was dissolved in ethanol solution $\left(\mathrm{V}_{\text {ethanol }}: \mathrm{V}_{\mathrm{H} 2 \mathrm{O}}=80: 20\right)$, and the $\mathrm{pH}$ of the solution was adjusted to 4 to prepare PFDTS solution. The CS@Ag/plant fiber was immersed in the PFDTS solution for $10 \mathrm{~s}$ and then removed and dried at 70 ${ }^{\circ} \mathrm{C}$ for $1 \mathrm{~h}$ to make the surface of the CS@Ag/plant fiber membrane hydrophobic (Zhou et al., 2017). The corresponding membranes formed by CS@Ag-12, CS@Ag-21, CS@Ag-29, and CS@Ag-36 are named S1, S2, S3, S4; the pure plant fiber membranes are named S0 (the volume fraction of Ag in the S1, S2, S3, and S4 are $9 \%, 15 \%, 19 \%$, and $22 \%$, respectively).

2.4. Characterization. The crystallographic information of CS@Ag core-shell fibers was obtained by X-ray diffraction spectra (XRD, Rigaku Co., Ultima IV) equipped with a monochromatized Cu Ka radiation $(\lambda=$ $1.5418 \AA$ ). The spectra were acquired by scanning the samples with a rate of $0.02^{\circ}(2 \theta)$ per second over the angular $2 \theta$ range 10 80 ${ }^{\circ}$. The morphologies of CS@Ag core-shell fibers and CS@Ag/plant fiber membrane were examined by scanning electron microscopy (SEM, FEI Co., Nova NanoSEM 450). The thermal stabilities of CS@Ag core-shell fibers were analyzed by thermogravimetric analyzer (TGA, Netzsch, TG209F1). The measurement was heated from $30^{\circ} \mathrm{C}$ to $700{ }^{\circ} \mathrm{C}$ with a heating rate of $10^{\circ} \mathrm{C} / \mathrm{min}$ in the $\mathrm{N}_{2}$ atmosphere. The thermal conductivities of CS@Ag/plant fiber membranes were measured by laser thermal conductivity analyzer (NETZSCH, LFA 427) at $25^{\circ} \mathrm{C}$. The surface temperature change of CS@Ag/plant fiber membrane was measured by a thermal imaging camera (Testo SE and Co., Testo 875- 
2i). The $\mathrm{PM}_{2.5}$ removal efficiency of the fiber membrane was checked with particle filtration tester (Suzhou Suxin Environmental Technology Co., Ltd., SX-L1056). The air permeability of the fiber membrane is measured by automatic air permeability tester (Ningbo Textile Instrument Factory, YG461G).

2.5. Antibacterial Testing. The antibacterial activity of the fiber membranes against Escherichia coli (E. coli, a Gram-negative bacterium) and Staphylococcus aureus (S. aureus, Gram-positive bacteria) was evaluated by viable-cell-counting method (Abdelgawad et al., 2014; Hamed et al., 2020; Liu et al., 2021). Five groups of fiber membranes were tested, including S0, S1, S2, S3, and S4. Briefly, each group of fiber membranes $(1 \mathrm{~g})$ was put into $100 \mathrm{ml}$ of bacteria/nutrient solution, and the bacteria/nutrient solution was incubated in a shaking incubator at $37^{\circ} \mathrm{C}$ for $24 \mathrm{~h}$. After the exposure of the bacteria to fiber membranes, the bacteria/nutrient solution was diluted with saline. And then $0.1 \mathrm{ml}$ of the bacteria solution was taken out and spin-coated on the nutrient agar plate. Nutrient agar plates were incubated at $37^{\circ} \mathrm{C}$ for $24 \mathrm{~h}$, and the numbers of surviving colonies were counted. Three parallel experiments were performed for each sample. These results were compared with the number of colonies in the control group that was not exposed to the fiber membrane. The antibacterial rate (\%) was calculated according to the following equation (Liu et al., 2021; Xiong et al., 2019):

$$
\text { antibacterial rate }(\%)=\frac{\text { CCCG-CCEG }}{\text { CCCG }} \times 100 \%
$$

where CCCG refers to the colony count of the control group and CCEG refers to the colony count of the experimental group.

\section{Results And Discussion}

Figure 2a presents optical photographs of the solution during the preparation of CS@Ag core-shell fibers. The AgNPs solution should be initially yellow, then brown, and finally black (Mohammadalinejhad et al., 2019; Wang et al., 2016). However, the solution has been clarified during the experiment. only the color of the CS fiber changed as described above. With continuous reduction of $\mathrm{Ag}^{+}$, the amino and hydroxyl groups on the surface of CS fibers acted as anchors for AgNPs via the atom-by-atom growth, and finally CS fibers were in situ coated with reduced AgNPs (Huo et al., 2020; Shen and Feng, 2018). To verify the amount of the reduced AgNPs that were adhered to the fibers, the CS fibers were weighed before and after the treatment. The utilization rate of AgNPs was calculated by the following formula:

$$
\text { utilization rate of } \mathrm{AgNPs}(\%)=\frac{\mathrm{m}_{3}-\mathrm{m}_{1}}{\mathrm{~m}_{2} \times \frac{\mathrm{M}_{\mathrm{Ag}}}{\mathrm{M}_{\mathrm{AgNO}}}} \times 100 \%
$$

Where $\mathrm{m}_{1}, \mathrm{~m}_{2}, \mathrm{~m}_{3}$ refer to the mass of CS fibers, $\mathrm{AgNO}_{3}$, and CS@Ag core-shell fibers, respectively $\left(\mathrm{M}_{\mathrm{Ag}}=\right.$ 108. $\mathrm{M}_{\mathrm{AgNO3}}=170$ ). As shown in Figure $2 \mathrm{~b}$, the utilization rate of AgNPs is between $92-97 \%$, indicating 
that $92-97 \%$ of the reduced AgNPs adhered to the fibers. The remaining 3-8\% of AgNPs should be silver mirrors (figure $2 \mathrm{a}$ ) attached to the inner wall of the beaker.

To determine whether the reduction product is elemental silver or not, the CS@Ag core-shell fibers were analyzed by X-ray diffraction (XRD) analysis. It can be seen from Figure $2 \mathrm{c}$ that there are four main peaks at $2 \theta$ values of $38.5^{\circ}, 44.6^{\circ}, 64.8^{\circ}$, and $77.7^{\circ}$. These peaks correspond to $(1,1,1),(2,0,0),(2,2,0),(3,1,1)$ diffraction planes of Ag crystals (Ming et al., 2019; Parida et al., 2020; Shen and Feng, 2018), which further corroborates that the surface of the CS fiber is indeed AgNPs. With the increase of $\mathrm{AgNO}_{3}$ concentration, the diffraction peak at $38.56^{\circ}$ becomes more intense, and the half-value width decreases from 0.697 (CS@Ag-12) to $0.468^{\circ}$ (CS@Ag-36). This phenomenon shows that the crystalline grain size of AgNPs gradually increases and the crystals develop more intact with the increase of $\mathrm{AgNO}_{3}$ concentration (Wu et al., 2015; Ye et al., 2019).

Figure 2d is the thermogravimetric analysis (TGA) curves of the CS@Ag core-shell fibers with different AgNPs loadings. CS displays three stages of thermal weight loss. The first stage corresponds to the volatilization of water. The second stage is related to the breakage of the CS molecular skeleton unit. And the third stage stems from the carbonization of CS (Bazmandeh et al., 2020; Chen et al., 2020). After CS fibers were coated with AgNPs, the thermal weight loss of CS in the first stage is significantly slowed down. Here we boldly guess that it was because the AgNPs evenly encapsulate the CS fibers so that the water volatilization was drastically reduced and the thermal stability was improved. In addition, it can be seen from the remaining amount that the number of AgNPs adhering to the fiber gradually increases with the increase of $\mathrm{AgNO}_{3}$ concentration.

To verify the above-mentioned conjecture of the TGA results, scanning electron microscopy (SEM) and energy dispersive spectroscopy (EDS) were used to characterize the surface morphology and element of pure CS and CS@Ag core-shell fibers with different AgNPs loadings. Figure 3a $a_{1} \sim a_{2}$ show the SEM images of CS fiber, the surface of which is smooth and free of impurities. Figure $3 b_{1} \sim b_{2}, 3 c_{1} \sim c_{2}, 3 d_{1} \sim d_{2}$, $3 e_{1} \sim e_{2}$ show the SEM images of CS@Ag-12,CS@Ag-21, CS@Ag-29 and CS@Ag-36 fibers, respectively. In the SEM images, it can be seen that AgNPs grow uniformly on the surface of the CS fiber until totally wrap it, which confirms the above conjecture. When the concentration of $\mathrm{AgNO}_{3}$ is low, the morphology of CS fibers is vaguely visible (figure $3 b_{2}$ ) because the loading of AgNPs is less and the size of AgNPs is small at this time. As the concentration of $\mathrm{AgNO}_{3}$ increases, the loading and particle size of AgNPs increases, completely encapsulating CS fibers to form a core-shell structure. The universal meter was used to make a rough measurement of the resistance of the CS@Ag core-shell fibers. Undoubtedly, the resistance of $\mathrm{CS}$ fibers is infinite (Figure $\left.3 \mathrm{a}_{3}\right)$ because $\mathrm{CS}$ is not conductive. Interestingly, the resistances of CS@Ag-12,CS@Ag-21, CS@Ag-29 and CS@Ag-36 core-shell fibers are $40.9 \Omega$ (Figure 3b 3 ), $6.1 \Omega$ (Figure $3 c_{3}$ ), $0.3 \Omega$ (Figure $3 d_{3}$ ), $0.1 \Omega$ (Figure $3 e_{3}$ ), respectively. Conductive AgNPs formed a continuous phase on the surface of CS fibers, making the CS fibers conductive. And with the increase of $\mathrm{AgNO}_{3}$ concentration, the core-shell structure was improved, so the resistance of CS@Ag core-shell fibers gradually decreased. The EDS scanning test of carbon $(\mathrm{C})$, oxygen $(\mathrm{O})$, nitrogen $(\mathrm{N})$, and silver $(\mathrm{Ag})$ was 
carried to investigate the composition at the surface of CS@Ag core-shell fibers (figures $3 e_{4} \sim \mathrm{e}_{6}$ ). The C, 0 , and $\mathrm{N}$ elements are originated from the long carbon chain of CS and the Ag element is derived from AgNPs (Chen et al., 2020). Based on the results of elemental mappings, it can be seen that the above Ag elements are evenly and tightly distributed on the fiber surface, and the total mass is as high as $87.2 \mathrm{wt} \%$. The EDS results once again proved the formation of the core-shell structure.

The prepared CS@Ag core-shell fibers were combined with plant fibers to make functional CS@Ag/plant fiber membranes through a simple suction filtration method. To predict whether the CS@Ag/plant fiber membranes can be applied to the filter layer of masks, some key indicators related to the quality of the face mask, including air permeability, removal efficiency, and hydrophobicity, were tested. Air permeability is closely related to wearing comfort. Figure 4a exhibits the air permeability of commercial PP face mask, pure plant fiber membrane, and CS@Ag/plant fiber membranes. As the "binder" between CS@Ag coreshell fibers, the main component of plant fibers is cellulose. The strong hydrogen bonds between cellulose can make the fiber membrane tightly bonded and reduce air voids, which can be seen from the low air permeability of the pure plant fiber membrane (only $27.5 \mathrm{~mm} \cdot \mathrm{s}^{-1}$ ) (Wang et al., 2018; Wang et al., 2021; Zhou et al., 2021). Although the addition of CS@Ag core-shell fibers would break the hydrogen bonds between plant fibers, the density of CS@Ag core-shell fibers increased with the addition of AgNPs. When the same quality of CS@Ag core-shell fibers was added, the number of CS@Ag core-shell fibers will decrease. Eventually, the structure of CS@Ag/plant fiber membrane changed from loose to relatively compact. The air permeability of the sample is reduced from $349.7 \mathrm{~mm} \cdot \mathrm{s}^{-1}(\mathrm{~S} 1)$ to $260.2 \mathrm{~mm} \cdot \mathrm{s}^{-1}$ (S4). Compared with the commercial PP face mask with an air permeability of $167.4 \mathrm{~mm} \cdot \mathrm{s}^{-1}$, the CS@Ag/plant fiber membrane are much more breathable.

If people are upon long-term exposure to $\mathrm{PM}_{2.5}, \mathrm{PM}_{2.5}$ particles will permeate through human respiratory tract and cause harm to them (Liu et al., 2020a). Therefore, the face mask with perfect $\mathrm{PM}_{2.5}$ removal efficiency plays an important role in human body safety protection (Liao et al., 2021a). Figure $4 \mathrm{~b}$ shows the $\mathrm{PM}_{2.5}$ removal efficiency of commercial PP face mask, pure plant fiber membrane, and CS@Ag/plant fiber membrane. $\mathrm{PM}_{2.5}$ removal efficiency has a certain correlation with air permeability and air void size. The $\mathrm{PM}_{2.5}$ removal efficiency of the pure plant fiber membrane itself is better, with a removal efficiency of $98.7 \%$. Therefore, the addition of pure plant fiber will effectively improve the $\mathrm{PM}_{2.5}$ removal efficiency of CS@Ag/plant fiber membrane. With the increase of the AgNPs loading on the CS@Ag core-shell fiber, the air void size and air permeability decrease, and the removal efficiency of $\mathrm{PM}_{2.5}$ gradually increased from $86.7 \%$ (S0) to $94.8 \%$ (S4). The $\mathrm{PM}_{2.5}$ removal efficiency of CS@Ag-36/plant fiber membrane surpasses the performance of commercial PP masks with a $\mathrm{PM}_{2.5}$ removal efficiency of $94.2 \%$.

Since the COVID-19 spread through respiratory droplets, the hydrophobicity of filter layer for masks is a contributing factor to their service life and antibacterial activity (Kumar et al., 2020). To confirm whether $\mathrm{C}_{13} \mathrm{H}_{13} \mathrm{~F}_{17} \mathrm{O}_{3} \mathrm{Si}$ successfully modified fiber membranes, hydrophilicity test for the CS@Ag/plant fiber membrane before and after treatment were carried out, and the results are summarized in Figure $4 \mathrm{c}$ and 4d. As shown in Figure 4c, the treated membrane has excellent hydrophobicity, while the untreated 
membrane is hydrophilic, and the water droplets are immediately absorbed by it. Figure $4 \mathrm{~d}$ summarizes the water contact angle data for pure plant fiber membrane and CS@Ag/plant fiber membrane with different AgNPs loadings. The contact angles of treated samples were all greater than $140^{\circ}$, which indicated that the fiber membranes treated with $\mathrm{C}_{13} \mathrm{H}_{13} \mathrm{~F}_{17} \mathrm{O}_{3} \mathrm{Si}$ changed from a hydrophilic material to a high hydrophobic material. The hydrophobicity of the fiber membranes endows itself with certain selfcleaning and antifouling properties (Wu et al., 2016).

Besides the satisfactory $\mathrm{PM}_{2.5}$ removal efficiency and air permeability, the CS@Ag/plant fiber membrane has distinctive heat dissipation function. A laser thermal conductivity meter was used to measure the inplane and through-plane thermal conductivity of samples, and the results are summarized in Figures $5 a$ and $\mathrm{b}$. The in-plane thermal conductivity of the pure plant fiber membrane is $0.30 \mathrm{~W} \cdot \mathrm{m}^{-1} \cdot \mathrm{K}^{-1}$, and the through-plane thermal conductivity is $0.11 \mathrm{~W} \cdot \mathrm{m}^{-1} \cdot \mathrm{K}^{-1}$. The addition of CS@Ag core-shell fiber makes the thermal conductivity of CS@Ag/plant fiber membrane increase immediately. And with the increase of the AgNPs loading on the CS fiber, the thermal conductivity of CS@Ag/plant fiber membrane continues to increase. When the AgNPs loading on CS fibers is $36 \mathrm{vol} \%$, the in-plane thermal conductivity of CS@Ag/plant fiber membranes increases to $0.89 \mathrm{~W} \cdot \mathrm{m}^{-1} \cdot \mathrm{K}^{-1}$. Compared with commercial PP masks with in-plane thermal conductivity of $0.20 \mathrm{~W} \cdot \mathrm{m}^{-1} \cdot \mathrm{K}^{-1}$, the in-plane thermal conductivity of CS@Ag/plant fiber membranes is 4.45 times that of commercial PP masks, showing excellent heat dissipation performance. The thermal conductivity of the plant fiber itself is low, and the heat transfer rate in the plant fiber is slow, so the connection of the plant fiber is not the reason for the rapid increase of the in-plane thermal conductivity. From the surface SEM images of samples S0 and S4 in figure 5c, the reason for the increase in in-plane thermal conductivity can be seen. The thermal conductivity of AgNPs is as high as $429 \mathrm{~W} \cdot \mathrm{m}^{-}$ ${ }^{1} \cdot \mathrm{K}^{-1}$, so the heat transfer rate is fast on the surface of CS@Ag core-shell fiber. And the heat transfer rate increases with the increase of AgNPs loading. Therefore, the connection of CS@Ag core-shell fibers is the reason for the rapid increase in in-plane thermal conductivity. To satisfy the breathability of the fiber membrane when used as a mask, the cross-section of the fiber membranes entrains a large amount of air voids. The thermal conductivity of air is extremely low, only $0.023 \mathrm{~W} \cdot \mathrm{m}^{-1} \cdot \mathrm{K}^{-1}$, which results in a low through-plane thermal conductivity (Hu et al., 2021). Even though the loading of AgNPs on CS fibers is as high as 36\%, the through-plane thermal conductivity of the CS@Ag/plant fiber membranes is only 0.15 $\mathrm{W} \cdot \mathrm{m}^{-1} \cdot \mathrm{K}^{-1}$, which is 1.15 times that of commercial PP masks $\left(0.13 \mathrm{~W} \cdot \mathrm{m}^{-1} \cdot \mathrm{K}^{-1}\right)$.

To characterize the thermal management capability of plant fiber membranes and CS@Ag/plant fiber membranes, the surface temperature of the fiber membranes during heating was measured by an infrared thermal imager every $15 \mathrm{~s}$ (Zhang et al., 2019). The results are shown in Figure $5 \mathrm{~d} \sim \mathrm{e}$. At the first second, the surface temperatures of $S 0, S 1, S 2, S 3$, and $S 4$ are $18.1,18.4,18.6,18.9$, and $23.3^{\circ} \mathrm{C}$, respectively. After heating for $90 \mathrm{~s}$, the surface temperature of S0, S1, S2, S3, and S4 increased to 36.6, 37.9, 44.4, 50.1 , and $61.3^{\circ} \mathrm{C}$, respectively. As the loading of AgNPs increases, the corresponding surface temperature of each sample increases more rapidly. These results are consistent with the experimental results shown in Figure 5a b. The sample S4 was made into a mask and worn by the model at room temperature $\left(25^{\circ} \mathrm{C}\right)$. As shown in Figure $5 \mathrm{f}$, the surface temperature of the self-made fiber mask is quite different from 
that of the commercial PP face mask after wearing it for $1 \mathrm{~min}$. The average surface temperature of the self-made fiber mask increased from $24.3^{\circ} \mathrm{C}$ to $27.6^{\circ} \mathrm{C}$, while the average surface temperature of the commercial PP face mask only increased from $24.6^{\circ} \mathrm{C}$ to $25.7^{\circ} \mathrm{C}$. In contrast, self-made masks have a significant cooling effect by transmitting heat generated by the human body, while commercial PP masks block a large portion.

The connection of CS@Ag core-shell fibers not only endows CS@Ag/plant fiber membranes with good thermal conductivity but also low electrical resistance and high electrical conductivity (Lv et al., 2020). The resistance of CS@Ag/plant fiber membranes was measured by voltammetry. The principle of voltammetry is to measure the corresponding current by applying different voltages to the CS@Ag/plant fiber membrane. Then, the obtained data points are linearly fitted to obtain the resistance of the sample, as shown in Figure 6a. The resistances of samples S1, S2, S3, and S4 are 48.6, 37.4, 1.4, and $1.3 \Omega$, respectively. Electrical conductivity $(\sigma)$ is calculated using the following equation (Lim and Kitagawa, 2020; Xie et al., 2020) \

$$
\sigma=\frac{\mathrm{L}}{\mathrm{R} \times \mathrm{S}}
$$

where $L, R$, and $S$ are the sample length $(m)$, resistance, and electrode area $\left(m^{2}\right)$, respectively. The calculated conductivity of samples S1, S2, S3, and S4 are 55.1, 73.7, 2228.2, and $2236.1 \mathrm{~S} \cdot \mathrm{m}^{-1}$, respectively. CS@Ag core-shell fibers form a conductive network in the fiber membrane. As the loading of AgNPs increases, the resistance of the CS@Ag/plant fiber membrane decreases and the electrical conductivity becomes better.

The low resistance and high conductivity of CS@Ag/plant fiber membrane make them excellent candidates for use as an electrothermal material. In a low-temperature simulation room at $-11^{\circ} \mathrm{C}$, a portable power bank with an output voltage of $5 \mathrm{~V}$ and an output current of $2 \mathrm{~A}$ was used to power the CS@Ag-36/plant fiber membrane (sample S4), as shown in Figure 6c. The surface temperature of the fiber membrane was observed by an infrared thermal imager at a certain interval. The surface temperatures and the corresponding infrared thermal image are shown in figure $6 \mathrm{~d} \sim \mathrm{e}$. In the lowtemperature simulation chamber, the surface temperature of the membrane is only $3^{\circ} \mathrm{C}$. After energizing, the surface temperature of the film rises immediately and reaches the maximum temperature of $30.2^{\circ} \mathrm{C}$ when energized for $10 \mathrm{~min}$. Subsequently, the temperature dropped slightly. After energizing for a long time, the temperature is maintained at $21.4^{\circ} \mathrm{C}$, which is $18.4^{\circ} \mathrm{C}$ higher than the surface temperature of the membrane without electric heating. The CS@Ag/plant fiber membranes can provide heat to the human body in a cold environment.

As shown in Figure 6f, the power bank was used to power CS@Ag/plant fiber membrane at room temperature $\left(25^{\circ} \mathrm{C}\right)$. After $1 \mathrm{~min}$, the temperature of CS@Ag/plant fiber membrane can reach above $80{ }^{\circ} \mathrm{C}$ (figure $6 \mathrm{~g}$ ). Since COVID-19 can be inactivated within $30 \mathrm{~min}$ at $56^{\circ} \mathrm{C}$ (Chin et al., 2020), our findings confirm that CS@Ag/plant fiber membrane can inactivate COVID-19 with benefits of no added costs, 
chemicals, or work time. When people go out, CS@Ag/plant fiber membrane can not only block viruses and particles but also dissipate heat in a hot environment and keep warm in a cold environment. When people get home, it can be energized to sterilize and inactivate viruses as shown in Figure $6 \mathrm{~h}$.

When tenacious pathogens accumulate on the mask, improper use and disposal of the face mask may cause the risk of secondary infection to the wearer (Mahat et al., 2021). Therefore, antibacterial properties are also one of the important properties of masks. E. coli and S. aureus are typical representatives of Gram-negative bacteria and Gram-positive bacteria respectively and are also the most common bacteria in life (Liu et al., 2020b). We examined the antibacterial properties of fiber membranes against $E$. coli and S. aureus. Figure $7 \mathrm{a}$ is optical images of bacterial culture plates, showing the antibacterial activity of each fiber membrane against $E$. coli and $S$. aureus at the same dilution concentration. After $24 \mathrm{~h}$ of culture, the bacteria in the bacterial culture dish of the plant fiber membrane were metabolized vigorously. In contrast, the number of two kinds of colonies in the bacterial culture dish of CS@Ag/plant fiber membrane was significantly reduced. The quantitative analysis results of the antibacterial properties of the fibrous membranes (Figure 7b) show that the antibacterial rates of the plant fibers membrane against $E$. coli and S. aureus are only $30.99 \%$ and $20.82 \%$. The antibacterial rate of CS@Ag/plant fiber membrane against $E$. coli and S. aureus is above 99\%. This is because CS@Ag core-shell fibers in the fibrous membrane will release $\mathrm{Ag}^{+}$when they come into contact with bacteria, and $\mathrm{Ag}^{+}$has excellent antibacterial properties. The antibacterial mechanism diagram is shown in Figure 7c. The cell membrane surfaces of both Gram-negative bacteria and positive bacteria are negatively charged, and $\mathrm{Ag}^{+}$are positively charged. So, $\mathrm{Ag}^{+}$is easily electrostatically adsorbed on the surface of the cell membrane, leading to the destruction of the cell surface balance and the leakage of intracellular substances. In addition, $\mathrm{Ag}^{+}$can interact with thiol groups in proteins to promote the production of active oxygen, which will damage the protein and DNA and eventually lead to the death of bacteria (Liu et al., 2021; Mohammadalinejhad et al., 2019). The antibacterial experiment results prove that CS@Ag/plant fiber membranes have excellent antibacterial properties, and can be used as a mask filter to filter inhaled or exhaled bacteria, reducing the spread of bacteria.

\section{Conclusions}

In this study, the concerns of thermal comfort and environmental impacts by commercial PP masks have been addressed by fabricating multifunctional and eco-friendly masks through in-situ reduction of $\mathrm{Ag}^{+}$ and simple suction filtration method. The raw materials for our mask were CS and plant fibers, which are inherently biodegradable and eco-friendly. Utilization of these biodegradable materials instead of biodegradable PP as the raw materials for the production of masks can significantly reduce their impacts on environment. The CS@Ag core-shell fiber prepared by in-situ reduction of $\mathrm{Ag}^{+}$forms a conductive and thermal network in the mask. Therefore, the in-plane thermal conductivity of masks is 4.45 times higher than that of commercial masks, exhibiting preeminent heat dissipation. And the fabricated masks can be 
electrically heated to warm the wearer in a cold environment and disinfect COVID-19 facilely at room temperature. Meanwhile, the in-situ reduced AgNPs endow masks with superior antibacterial properties, exhibiting the high inhibition of E. coli and $S$. aureus exceeding $99.0 \%$. Considering the present challenges due to the COVID-19 pandemic, the prepared CS@Ag/plant fiber membranes exhibit has broad application prospects for the filter layer of masks.

\section{Declarations}

\section{Acknowledgments}

This work was supported by the National Natural Science Foundation of China (51473097), the Sichuan Science and Technology Project (2019YJ0107), and the Opening Project of State Key Laboratory of Polymer Materials Engineering (Sichuan University) (sklpme2014-3-14).

\section{References}

1. Abdelgawad, A.M., Hudson, S.M., and Rojas, O.J. (2014). Antimicrobial wound dressing nanofiber mats from multicomponent (chitosan/silver-NPs/polyvinyl alcohol) systems. Carbohydrate Polymers 100, 166-178.

2. Bazmandeh, A.Z., Mirzaei, E., Fadaie, M., Shirian, S., and Ghasemi, Y. (2020). Dual spinneret electrospun nanofibrous/gel structure of chitosan-gelatin/chitosan-hyaluronic acid as a wound dressing: In-vitro and in-vivo studies. International Journal of Biological Macromolecules 162, 359373.

3. Chen, H., Ginzburg, V.V., Yang, J., Yang, Y., Liu, W., Huang, Y., Du, L., and Chen, B. (2016a). Thermal conductivity of polymer-based composites: Fundamentals and applications. Progress In Polymer Science 59, 41-85.

4. Chen, H.Y., Ginzburg, V.V., Yang, J., Yang, Y.F., Liu, W., Huang, Y., Du, L.B., and Chen, B. (2016b). Thermal conductivity of polymer-based composites: Fundamentals and applications. Progress in Polymer Science 59, 41-85.

5. Chen, J., Fan, L., Yang, C., Wang, S., Zhang, M., Xu, J., and Luo, S. (2020). Facile synthesis of Ag nanoparticles-loaded chitosan antibacterial nanocomposite and its application in polypropylene. International Journal of Biological Macromolecules 161, 1286-1295.

6. Chin, A.W.H., Chu, J.T.S., Perera, M.R.A., Hui, K.P.Y., Yen, H.-L., Chan, M.C.W., Peiris, M., and Poon, L.L.M. (2020). Stability of SARS-CoV-2 in different environmental conditions. Lancet Microbe 1, E10E10.

7. Choi, S., Jeon, H., Jang, M., Kim, H., Shin, G., Koo, J.M., Lee, M., Sung, H.K., Eom, Y., Yang, H.S., et al. (2021). Biodegradable, Efficient, and Breathable Multi-Use Face Mask Filter. Adv Sci (Weinh) 8, 2003155. 
8. Guo, Y., Zuo, X., Xue, Y., Tang, J., Gouzman, M., Fang, Y., Zhou, Y., Wang, L., Yu, Y., and Rafailovich, M.H. (2020). Engineering thermally and electrically conductive biodegradable polymer nanocomposites. Composites Part B-Engineering 189, 107905.

9. Hamed, A.A., Abdelhamid, I.A., Saad, G.R., Elkady, N.A., and Elsabee, M.Z. (2020). Synthesis, characterization and antimicrobial activity of a novel chitosan Schiff bases based on heterocyclic moieties. International Journal of Biological Macromolecules 153, 492-501.

10. Hu, Z., Yan, S., Li, X., You, R., Zhang, Q., and Kaplan, D.L. (2021). Natural Silk Nanofibril Aerogels with Distinctive Filtration Capacity and Heat-Retention Performance. ACS Nano 15, 8171-8183.

11. Huang, L., Xu, S., Wang, Z., Xue, K., Su, J., Song, Y., Chen, S., Zhu, C., Tang, B.Z., and Ye, R. (2020). Self-Reporting and Photothermally Enhanced Rapid Bacterial Killing on a Laser-Induced Graphene Mask. ACS Nano 14, 12045-12053.

12. Huo, D.X., Chen, B., Meng, G.W., Huang, Z.L., Li, M.T., and Lei, Y. (2020). Ag-Nanoparticles@Bacterial Nanocellulose as a 3D Flexible and Robust Surface-Enhanced Raman Scattering Substrate. Acs Appl Mater Inter 12, 50713-50720.

13. Kumar, A., Sharma, A., Chen, Y., Jones, M.M., Vanyo, S.T., Li, C., Visser, M.B., Mahajan, S.D., Sharma, R.K., and Swihart, M.T. (2020). Copper@ZIF-8 Core-Shell Nanowires for Reusable Antimicrobial Face Masks. Advanced Functional Materials, 2008054.

14. Kumar, P., Roy, S., Sarkar, A., and Jaiswal, A. (2021). Reusable MoS2-Modified Antibacterial Fabrics with Photothermal Disinfection Properties for Repurposing of Personal Protective Masks. ACS Appl Mater Interfaces 13, 12912-12927.

15. Li, Q., Yin, Y., Cao, D., Wang, Y., Luan, P., Sun, X., Liang, W., and Zhu, H. (2021). Photocatalytic Rejuvenation Enabled Self-Sanitizing, Reusable, and Biodegradable Masks against COVID-19. ACS Nano.

16. Liao, M., Liu, H., Wang, X., Hu, X., Huang, Y., Liu, X., Brenan, K., Mecha, J., Nirmalan, M., and Lu, J.R. (2021a). A technical review of face mask wearing in preventing respiratory COVID-19 transmission. Current Opinion in Colloid and Interface Science 52, 101417.

17. Liao, M., Liu, H., Wang, X., Hu, X., Huang, Y., Liu, X., Brenan, K., Mecha, J., Nirmalan, M., and Lu, J.R. (2021b). A technical review of face mask wearing in preventing respiratory COVID-19 transmission. Current Opinion in Colloid \& Interface Science 52.

18. Lim, D.-W., and Kitagawa, H. (2020). Proton Transport in Metal-Organic Frameworks. Chemical Reviews 120, 8416-8467.

19. Liu, F., Cheng, X., Xiao, L., Wang, Q., Yan, K., Su, Z., Wang, L., Ma, C., and Wang, Y. (2021). Insideoutside Ag nanoparticles-loaded polylactic acid electrospun fiber for long-term antibacterial and bone regeneration. International Journal of Biological Macromolecules 167, 1338-1348.

20. Liu, H., Cao, C., Huang, J., Chen, Z., Chen, G., and Lai, Y. (2020a). Progress on particulate matter filtration technology: basic concepts, advanced materials, and performances. Nanoscale 12, 437453. 
21. Liu, Y., Li, F., Guo, Z., Xiao, Y., Zhang, Y., Sun, X., Zhe, T., Cao, Y., Wang, L., Lu, Q., et al. (2020b). Silver nanoparticle-embedded hydrogel as a photothermal platform for combating bacterial infections. Chemical Engineering Journal 382.

22. Lv, X.H., Tang, Y., Tian, Q.F., Wang, Y.P., and Ding, T. (2020). Ultra-stretchable membrane with high electrical and thermal conductivity via electrospinning and in-situ nanosilver deposition. Composites Science and Technology 200.

23. Mahat, M.M., Sabere, A.S.M., Azizi, J., and Amdan, N.A.N. (2021). Potential Applications of Conducting Polymers to Reduce Secondary Bacterial Infections among COVID-19 Patients: a Review. Emergent Materials 4, 279-292.

24. Ming, T.S., Schleusener, A., Yermukhamed, D., Dietzek, B., and Sivakov, V. (2019). Silver mirror reaction as a simple method for silicon nanowires functionalization. Mater Res Express 6.

25. Mohammadalinejhad, S., Almasi, H., and Esmaiili, M. (2019). Simultaneous green synthesis and insitu impregnation of silver nanoparticles into organic nanofibers by Lythrum salicaria extract: Morphological, thermal, antimicrobial and release properties. Mater Sci Eng C Mater Biol Appl 105, 110115.

26. Mohammadzadeh Pakdel, P., and Peighambardoust, S.J. (2018). Review on recent progress in chitosan-based hydrogels for wastewater treatment application. Carbohydr Polym 201, 264-279.

27. Mohammed, M., Syeda, J., Wasan, K., and Wasan, E. (2017). An Overview of Chitosan Nanoparticles and Its Application in Non-Parenteral Drug Delivery. Pharmaceutics 9, 53.

28. Morabito, M., Messeri, A., Crisci, A., Pratali, L., Bonafede, M., Marinaccio, A., and Group, W.C. (2020). Heat warning and public and workers' health at the time of COVID-19 pandemic. Science of the Total Environment 738, 140347.

29. Parida, D., Simonetti, P., Frison, R., Bülbül, E., Altenried, S., Arroyo, Y., Balogh-Michels, Z., Caseri, W., Ren, Q., Hufenus, R., et al. (2020). Polymer-assisted in-situ thermal reduction of silver precursors: A solventless route for silver nanoparticles-polymer composites. Chemical Engineering Journal 389.

30. Patil, N.A., Gore, P.M., Jaya Prakash, N., Govindaraj, P., Yadav, R., Verma, V., Shanmugarajan, D., Patil, S., Kore, A., and Kandasubramanian, B. (2021). Needleless electrospun phytochemicals encapsulated nanofibre based 3-ply biodegradable mask for combating COVID-19 pandemic. Chemical Engineering Journal 416, 129152.

31. Prata, J.C., Silva, A.L.P., Walker, T.R., Duarte, A.C., and Rocha-Santos, T. (2020). COVID-19 Pandemic Repercussions on the Use and Management of Plastics. Environ Sci Technol 54, 7760-7765.

32. Shen, Z., and Feng, J. (2018). Highly Thermally Conductive Composite Films Based on Nanofibrillated Cellulose in Situ Coated with a Small Amount of Silver Nanoparticles. Acs Appl Mater Inter 10, 24193-24200.

33. Suh, D., Lee, S., Xu, C., Jan, A.A., and Baik, S. (2019). Significantly enhanced phonon mean free path and thermal conductivity by percolation of silver nanoflowers. Physical Chemistry Chemical Physics 21, 2453-2462. 
34. Wang, F., Yao, Y., Zeng, X., Huang, T., Sun, R., Xu, J., and Wong, C.-P. (2016). Highly thermally conductive polymer nanocomposites based on boron nitride nanosheets decorated with silver nanoparticles. RSC Advances 6, 41630-41636.

35. Wang, J.J., Xu, X.Z., Zhang, J., Chen, M.T., Dong, S.Y., Han, J.B., and Wei, M. (2018). MoisturePermeable, Humidity-Enhanced Gas Barrier Films Based on Organic/Inorganic Multilayers. Acs Appl Mater Inter 10, 28130-28138.

36. Wang, Z.Q., Cheng, F.C., Cai, H.C., Li, X.R., Sun, J.P., Wu, Y.Q., Wang, N.N., and Zhu, Y.Q. (2021). Robust versatile nanocellulose/polyvinyl alcohol/carbon dot hydrogels for biomechanical sensing. Carbohydrate Polymers 259.

37. Wu, C., Zhang, G., Xia, T., Li, Z., Zhao, K., Deng, Z., Guo, D., and Peng, B. (2015). Bioinspired synthesis of polydopamine/Ag nanocomposite particles with antibacterial activities. Materials Science \& Engineering C-Materials for Biological Applications 55, 155-165.

38. Wu, M., Li, Y., An, N., and Sun, J. (2016). Applied Voltage and Near-Infrared Light Enable Healing of Superhydrophobicity Loss Caused by Severe Scratches in Conductive Superhydrophobic Films. Advanced Functional Materials 26, 6777-6784.

39. Xie, L.S., Skorupskii, G., and Dinca, M. (2020). Electrically Conductive Metal-Organic Frameworks. Chemical Reviews 120, 8536-8580.

40. Xiong, S.-W., Zhang, P., Xia, Y., Fu, P.-G., and Gai, J.-G. (2019). Antimicrobial hexagonal boron nitride nanoplatelet composites for the thermal management of medical electronic devices. Materials Chemistry Frontiers 3, 2455-2462.

41. Xiong, S.W., Fu, P.G., Zou, Q., Chen, L.Y., Jiang, M.Y., Zhang, P., Wang, Z.G., Cui, L.S., Guo, H., and Gai, J.G. (2021). Heat Conduction and Antibacterial Hexagonal Boron Nitride/Polypropylene Nanocomposite Fibrous Membranes for Face Masks with Long-Time Wearing Performance. Acs Appl Mater Inter 13, 196-206.

42. Yang, A., Cai, L., Zhang, R., Wang, J., Hsu, P.-C., Wang, H., Zhou, G., Xu, J., and Cui, Y. (2017a). Thermal Management in Nanofiber-Based Face Mask. Nano Letters 17, 3506-3510.

43. Yang, A., Cai, L., Zhang, R., Wang, J., Hsu, P.C., Wang, H., Zhou, G., Xu, J., and Cui, Y. (2017b). Thermal Management in Nanofiber-Based Face Mask. Nano Letters 17, 3506-3510.

44. Yang, Y., He, R., Cheng, Y., and Wang, N. (2020). Multilayer-structured fibrous membrane with directional moisture transportability and thermal radiation for high-performance air filtration. ePolymers 20, 282-291.

45. Ye, H., Cheng, J., and Yu, K. (2019). In situ reduction of silver nanoparticles by gelatin to obtain porous silver nanoparticle/chitosan composites with enhanced antimicrobial and wound-healing activity. International Journal of Biological Macromolecules 121, 633-642.

46. Zhang, T., Sun, J., Ren, L., Yao, Y., Wang, M., Zeng, X., Sun, R., Xu, J.-B., and Wong, C.-P. (2019). Nacreinspired polymer composites with high thermal conductivity and enhanced mechanical strength. Composites Part A: Applied Science and Manufacturing 121, 92-99. 
47. Zhou, H., Wang, H., Niu, H., Zhao, Y., Xu, Z., and Lin, T.J.A.F.M. (2017). A waterborne coating system for preparing robust, self-healing, superamphiphobic surfaces. Advanced Functional Materials 27, 1604261.

48. Zhou, J., Fang, Z.Q., Cui, J.Y., Zhang, X., Qian, Y., Liu, W.F., Yang, D.J., and Qiu, X.Q. (2021). Woodinspired strategy to toughen transparent cellulose nanofibril films. Carbohydrate Polymers 259.

49. Zou, Q., Xiong, S.-W., Jiang, M.-y., Chen, L.-y., Zheng, K., Fu, P.-g., and Gai, J.-g. (2021). Highly thermally conductive and eco-friendly $\mathrm{OH}-\mathrm{h}-\mathrm{BN} /$ chitosan nanocomposites by constructing a honeycomb thermal network. Carbohydrate Polymers 266, 118127.

\section{Figures}

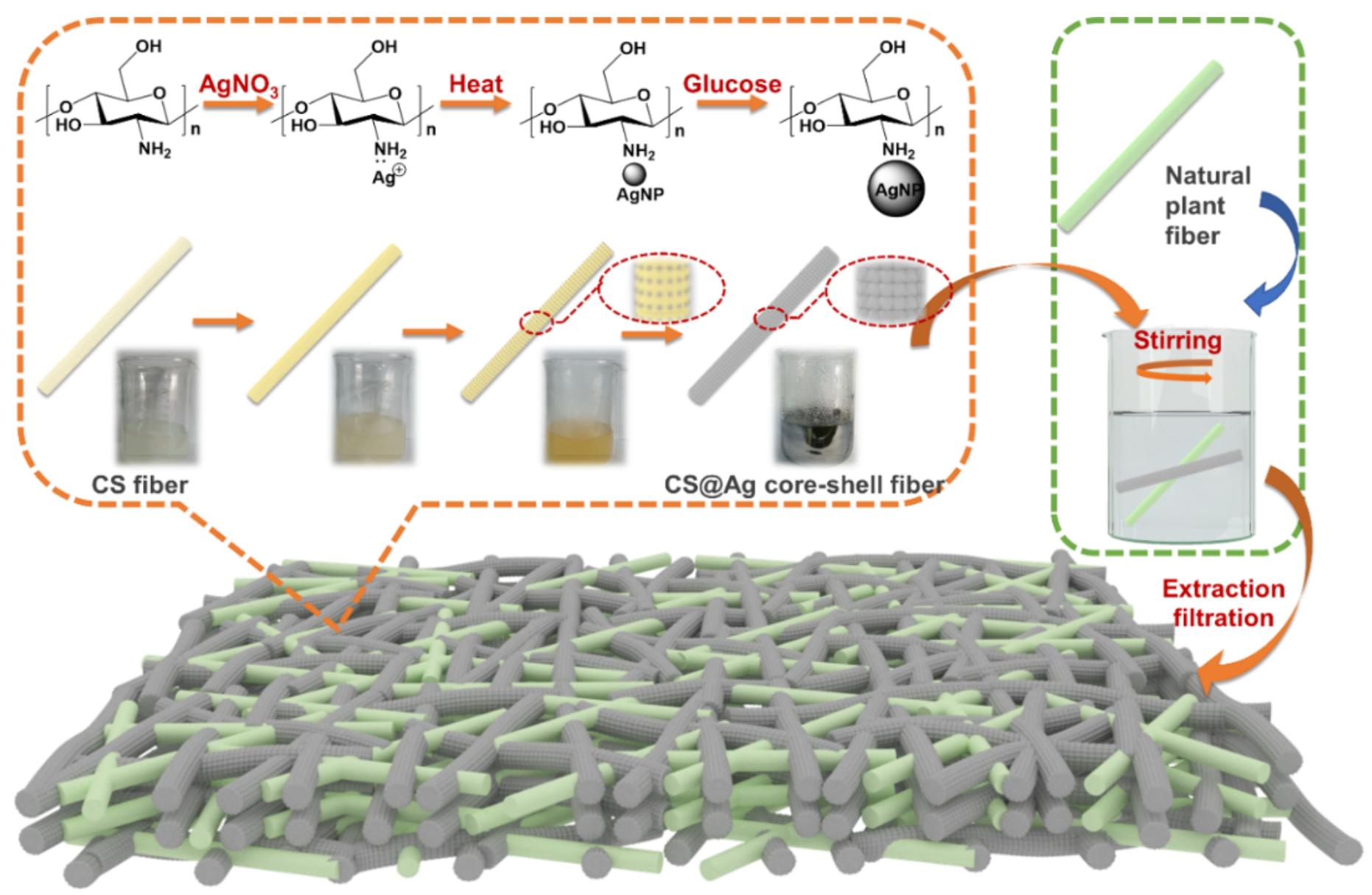

CS@Ag/ plant fiber membrane

\section{Figure 1}

The preparation process of the CS@Ag/plant fiber membrane 
(a)

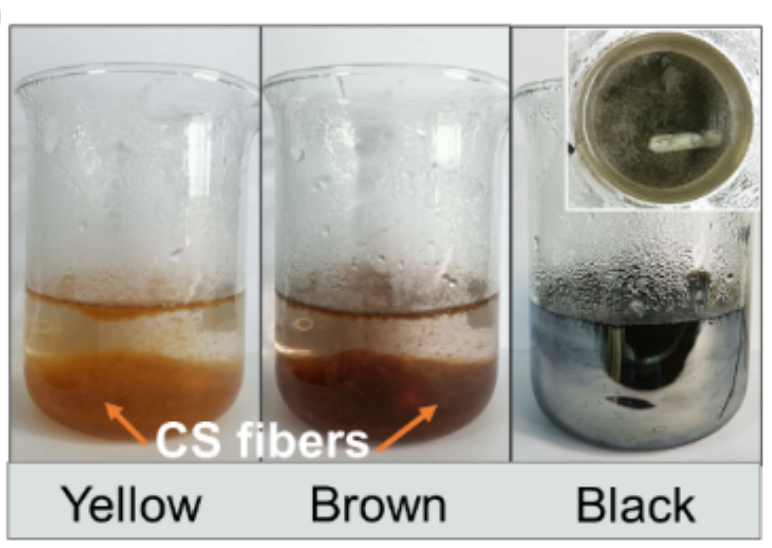

(c)

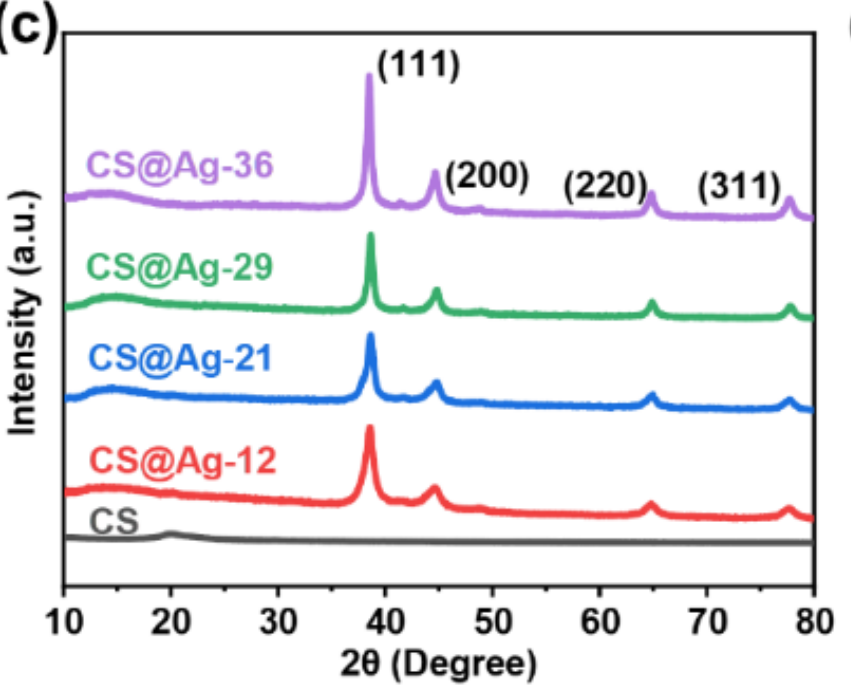

(b)

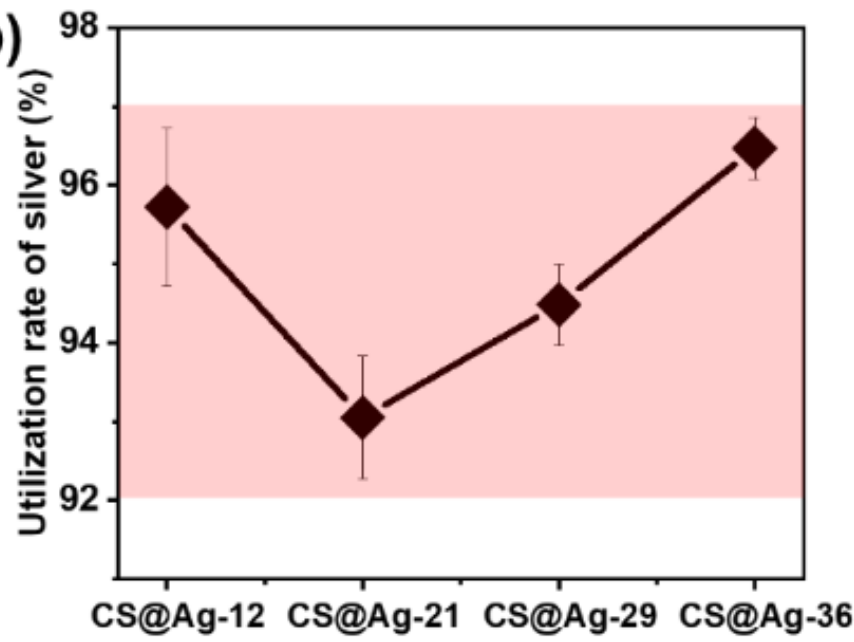

(d)

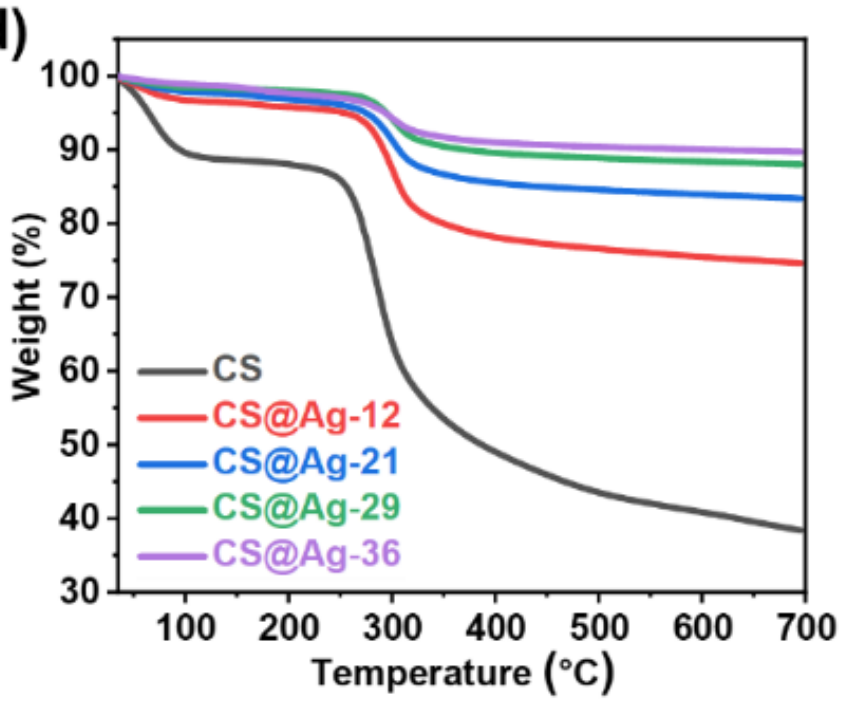

Figure 2

(a) Optical photographs of the solution during the preparation of CS@Ag core-shell fibers. (b) The utilization rate of AgNPs. (c) The XRD patterns and (d) TGA curves of pure CS and CS@Ag core-shell fibers with different AgNPs loadings. 

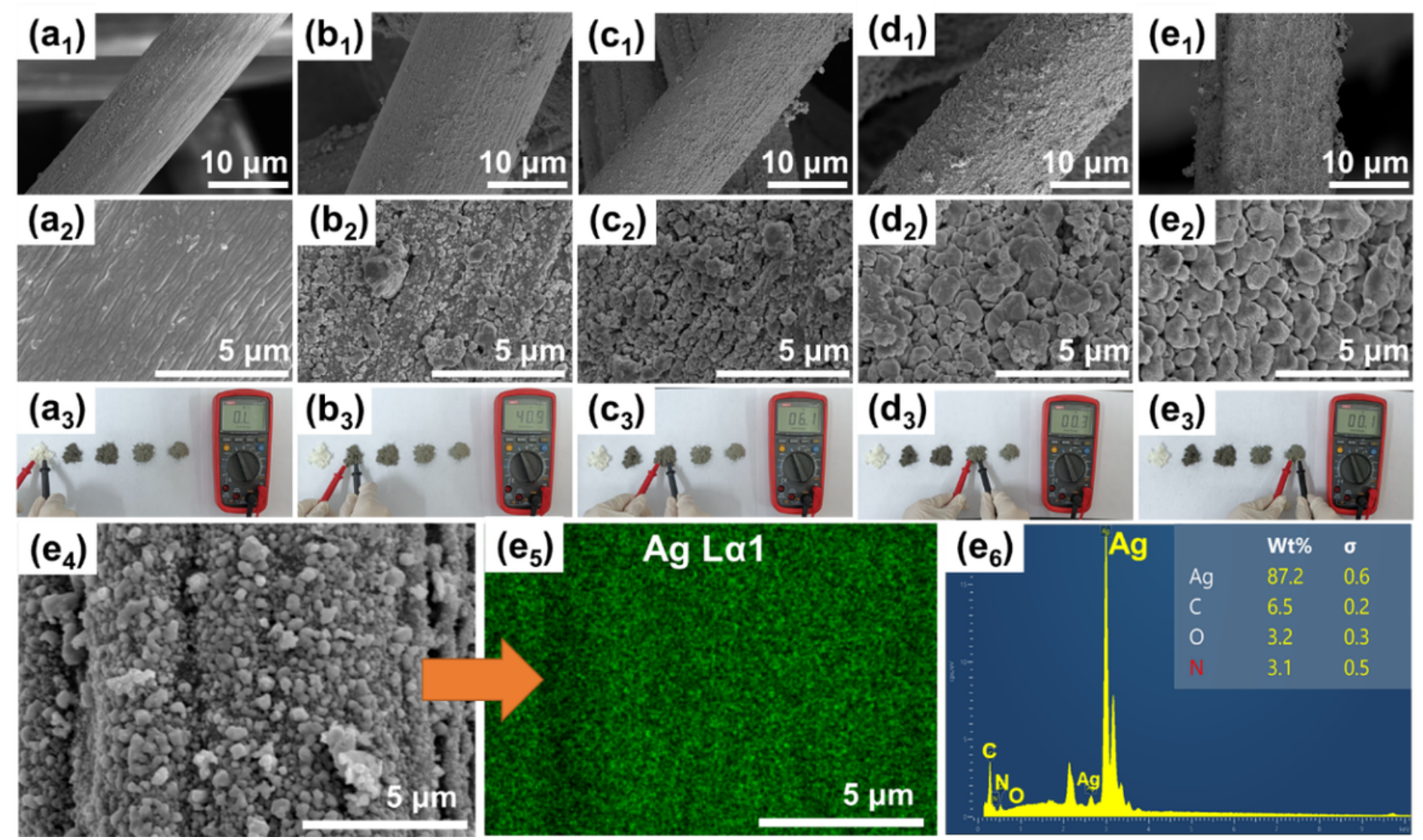

\section{Figure 3}

(a1 e2) SEM image and (a3 e3) photograph of universal meter test of pure CS and CS@Ag core-shell fibers with different AgNPs loadings (a: pure CS fibers, b: CS@Ag-12 core-shell fibers, c: CS@Ag-21 coreshell fibers, d: CS@Ag-29 core-shell fibers, e: CS@Ag-36 core-shell fibers). (e4) SEM image, (e5) corresponding EDS elemental maps of Ag element, and (e6) elemental mappings of CS@Ag-36 core-shell fibers. 

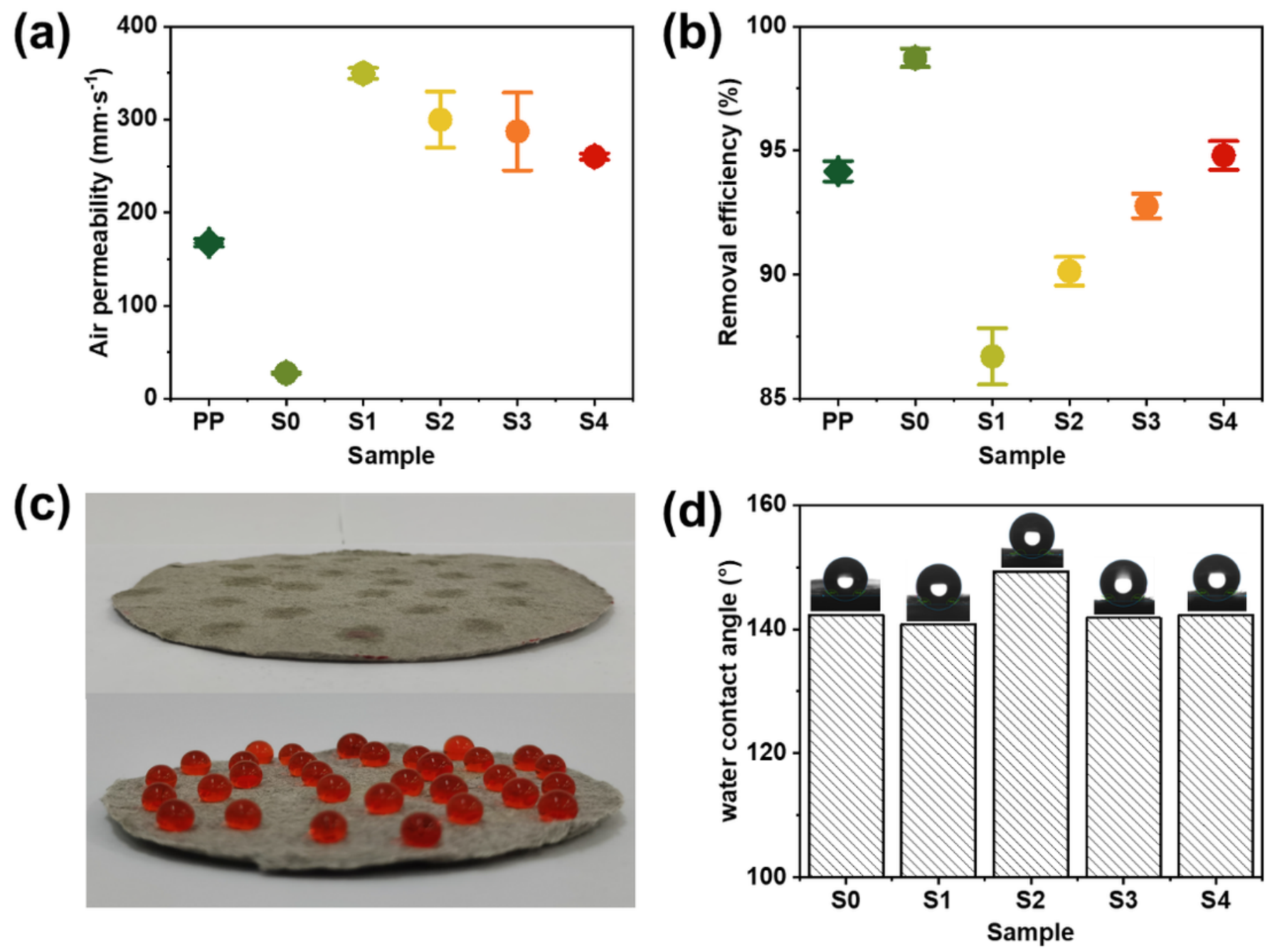

Figure 4

(a) The air permeability and (b) removal efficiency of commercial PP face mask, pure plant fiber membrane, and CS@Ag/plant fiber membrane with different AgNPs loadings. (c) Hydrophilicity experiment of CS@Ag/plant fiber membrane. (d) Water contact angle data for pure plant fiber membrane and CS@Ag/plant fiber membrane with different AgNPs loadings. 
(a)

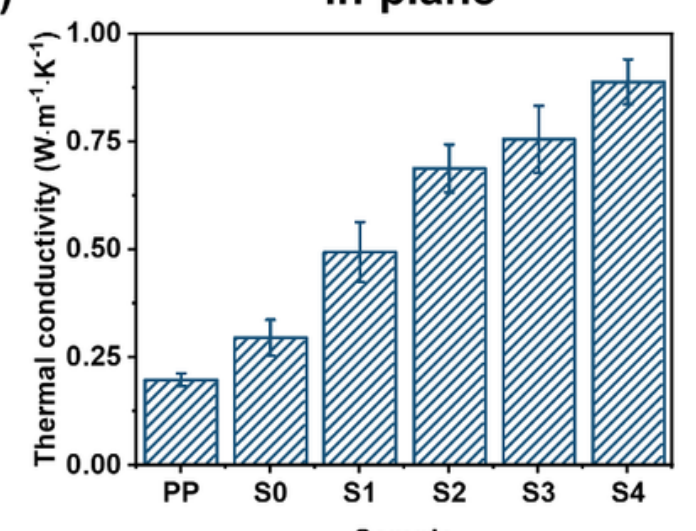

(c)

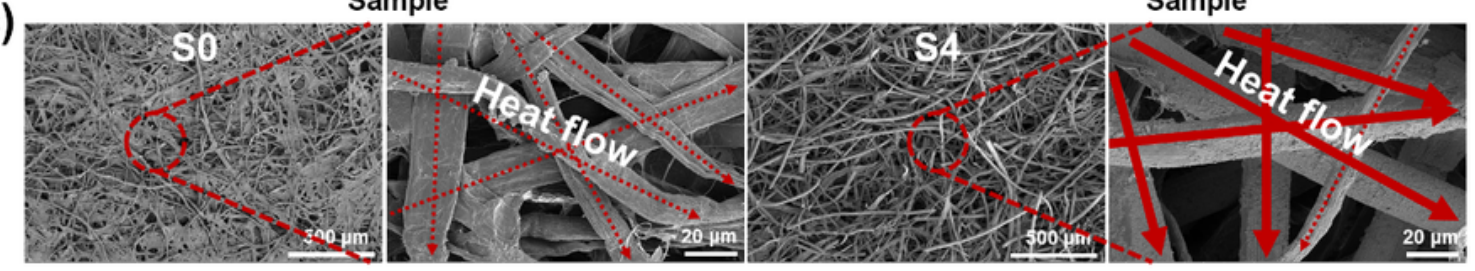

(d)

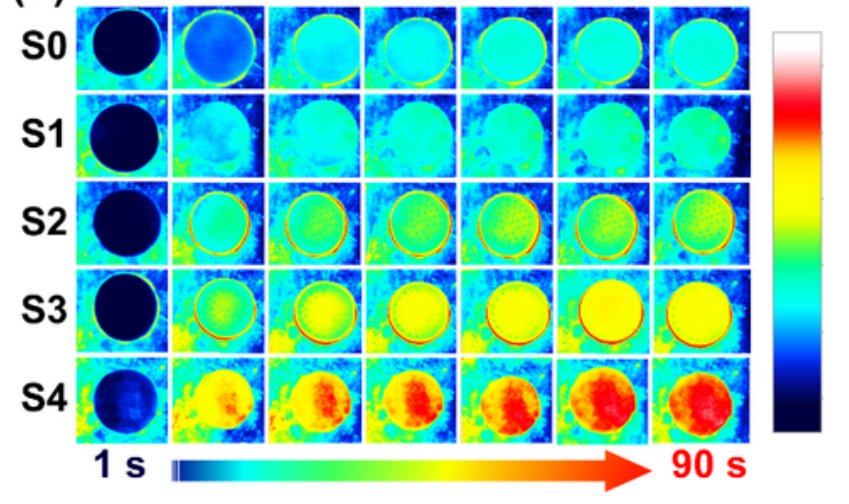

(b)

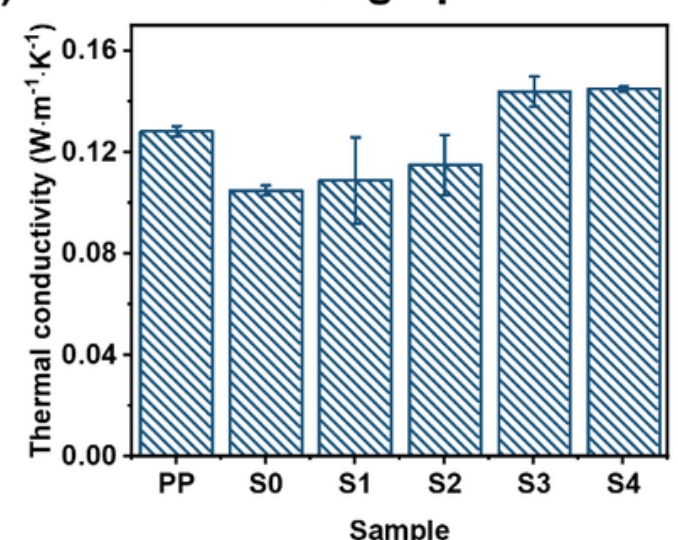

(e)

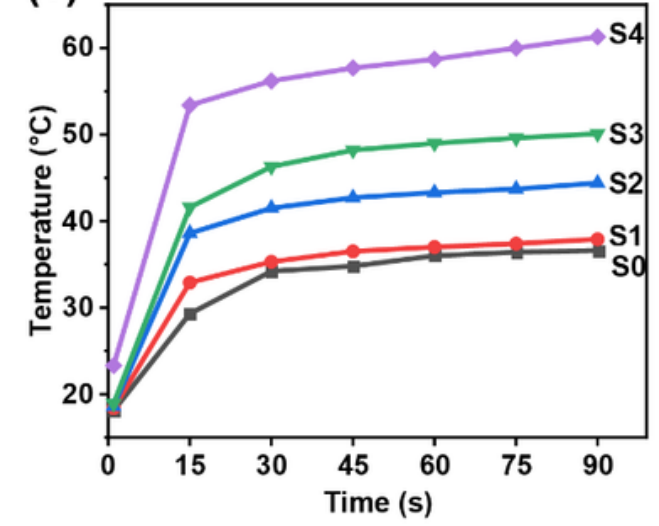

(f)

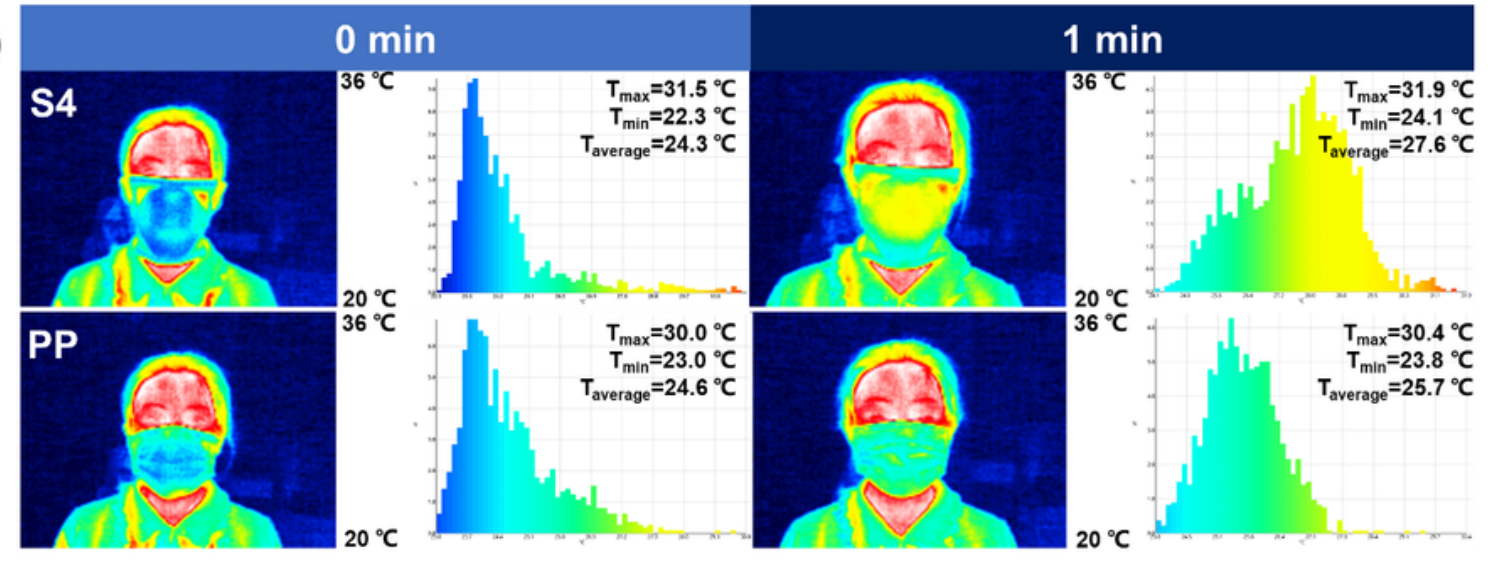

Figure 5

(a) In-plane and (b) through-plane thermal conductivity of samples. (c) the surface SEM images of samples S0 and S4. (d) Infrared thermal images of pure plant fiber membrane and CS@Ag/plant fiber membrane with different AgNPs loadings during the heating stage with time. (e) Surface temperature variation of the different samples with time elapse. (f) Infrared thermal images and the statistical result 
of room temperature when wearing sample S4 (CS@Ag-36/plant fiber membrane) and commercial PP face mask.

(a)

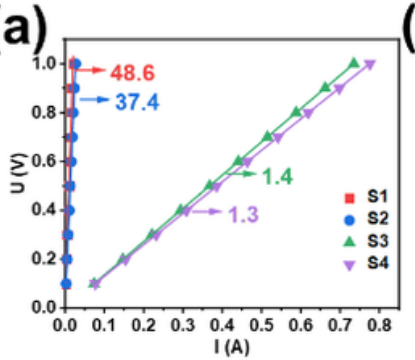

(e)

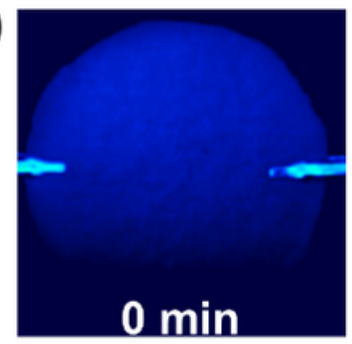

(f)

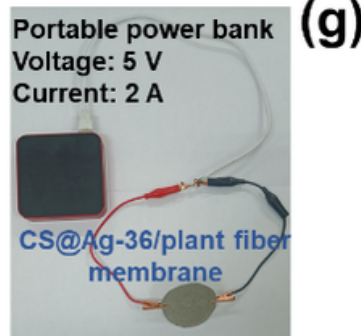

(b)

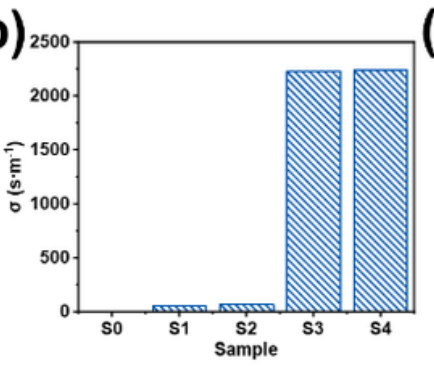

(c)
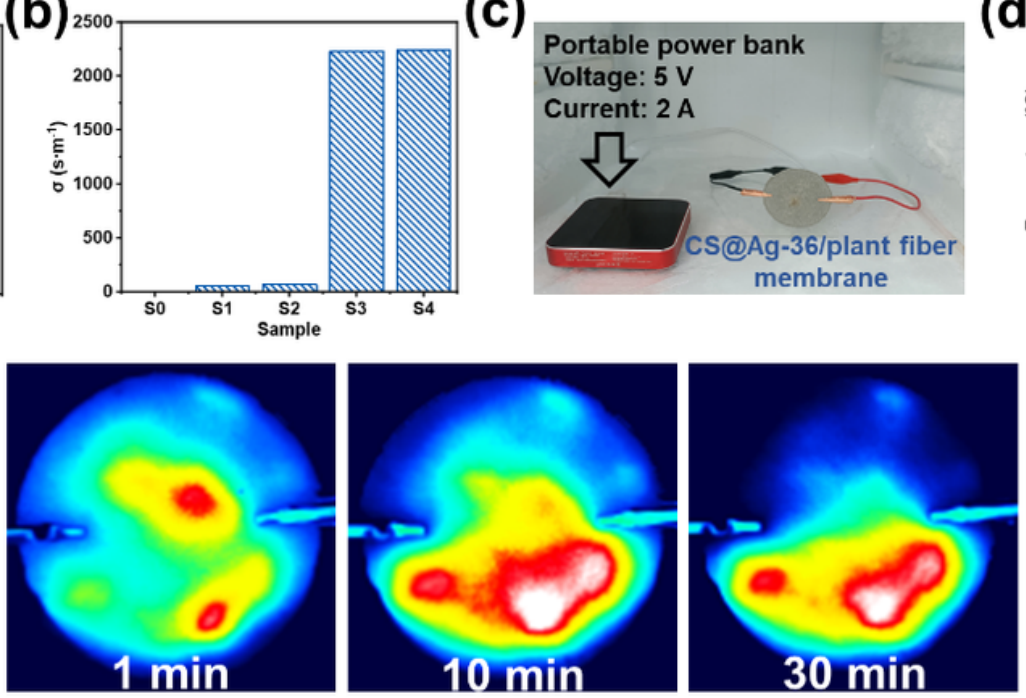

(h)

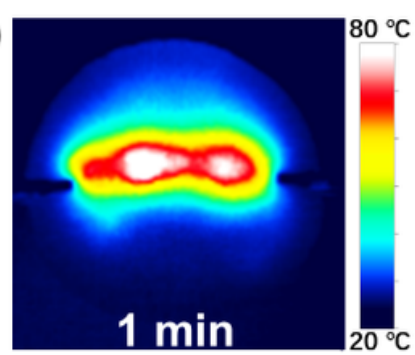

(d)
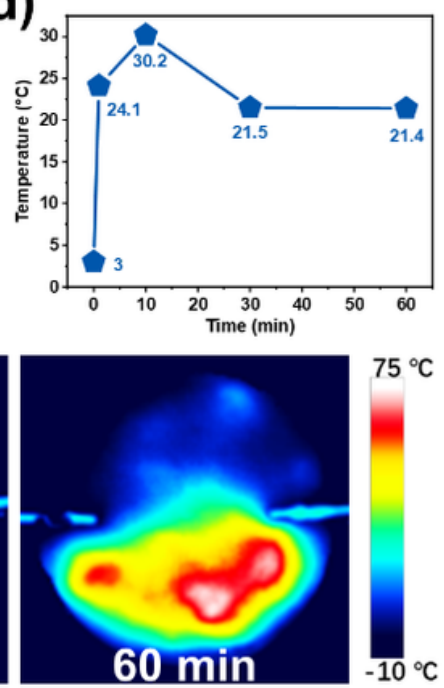

$60 \mathrm{~min}$

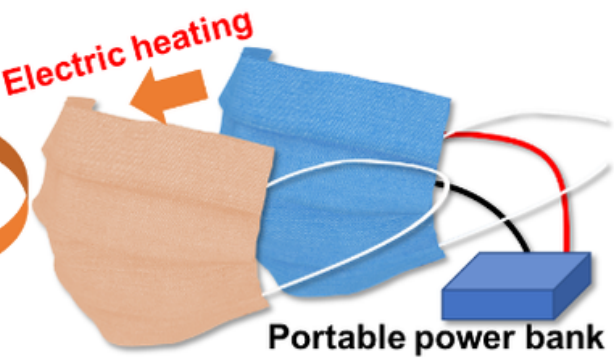

Figure 6

(a) resistance and (b) electrical conductivity of CS@Ag/plant fibers membrane with different AgNPs loadings. (c) Photo of sample S4 electrified in a cold environment. (d) Surface temperatures and (e) thermal images of sample S4 electrified with time in a cold environment. (f) Photo of sample S4 electrified at room temperature. (g) thermal image of sample S4 electrified after 1 min at room temperature. (h) Antibacterial schematic diagram of electric heating masks. 


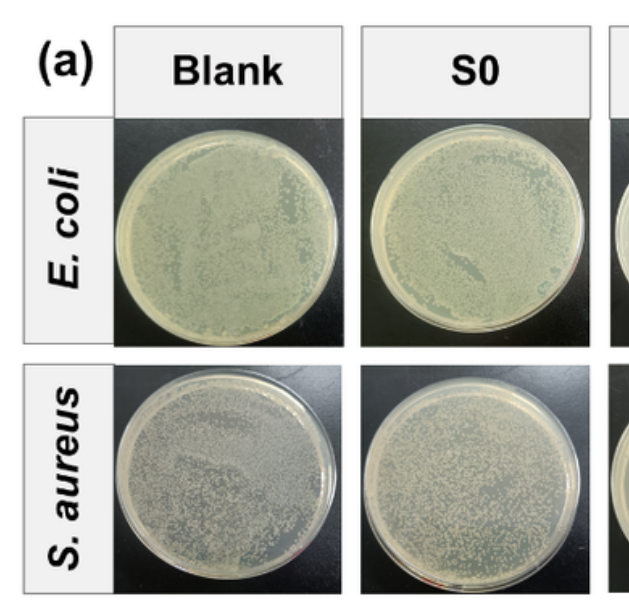

(b)

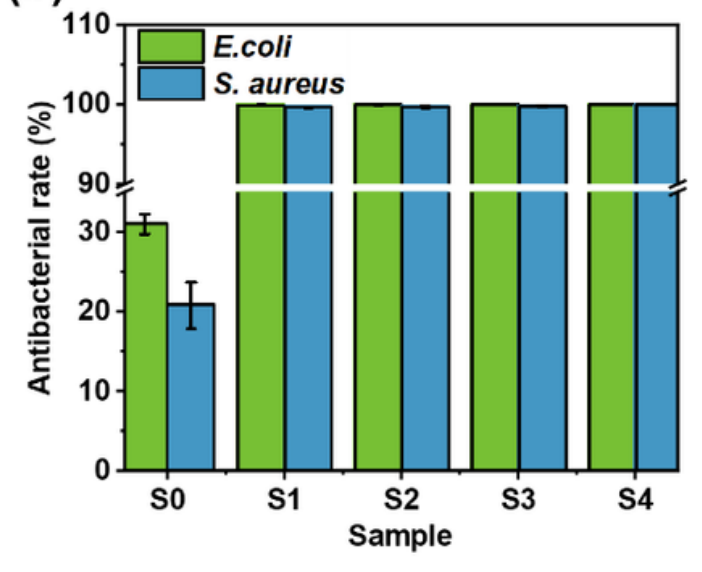

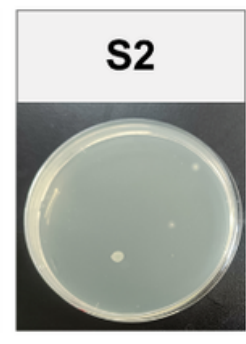
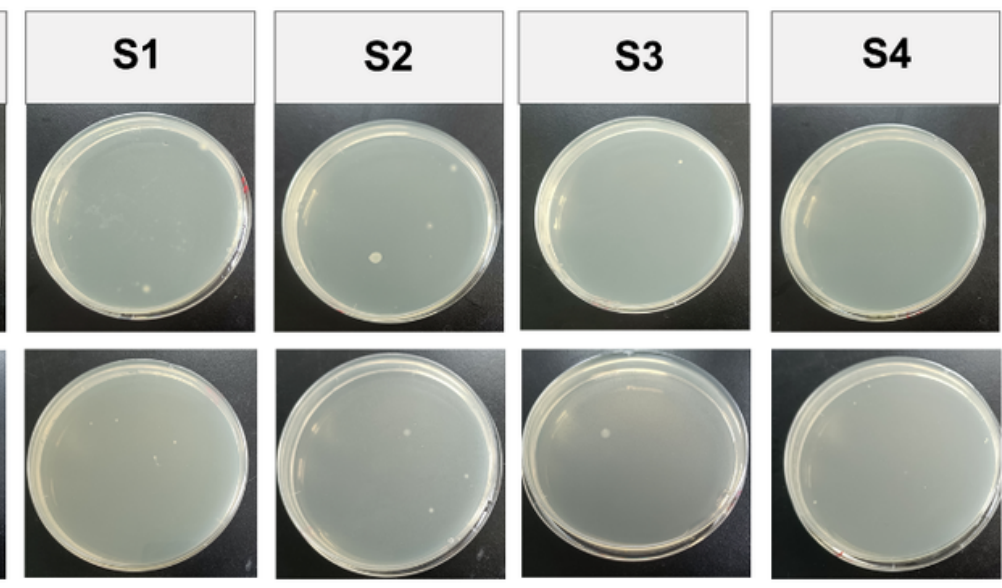

(c) Bacteria

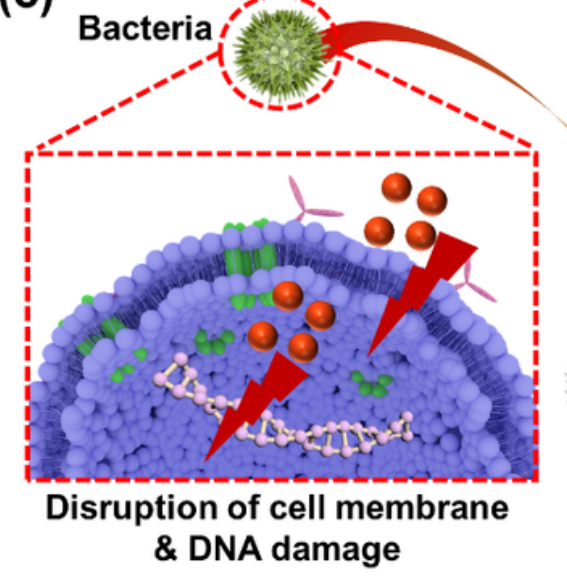

\section{Figure 7}

(a) Bacterial culture dish and (b) antibacterial rate of pure plant fibers membrane and CS@Ag/plant fibers membrane with different AgNPs loadings against E. coli and S. aureus. (c) Antibacterial mechanism of CS@Ag/plant fibrous masks.

\section{Supplementary Files}

This is a list of supplementary files associated with this preprint. Click to download.

- figs1.png

- Graphicalabstract.png 